\title{
A learner developer perspective: critiquing dominant practices and cultures within university spaces
}

\section{Sarah Parkes}

Newman University, Birmingham, UK

\section{Abstract}

This commentary reflects my evolving understanding of the problematic nature of identity and how this relates to notions of professional identity for those in learning development (LD) roles who engage with and produce research. If identity is, as Quinn (2010) asserts, boundary-less, and experienced as a perpetual becoming between multiplicities, what does this mean for questions of identity? This paper suggests that perpetual becoming is reflected in LD roles that operate within a third space, crossing or spanning the boundaries of traditional institutional sites of research, teaching or services, administration or knowledge transfer (Whitchurch, 2013). From such a place, LD practitioners can become what Ball (2007) calls cultural critics, who through their experiences and knowledge of the variety of institutional practices and cultures, are in an enviable place to critique them.

LD practitioners need to maintain a dialogical position that enables reflection-in-action (Schön, 2001) to understand and respond to the multiplicities present in competing individual, institutional and societal discourses. By way of an example, consider the contrast between the pervasive neo-liberal drive for quantification and performance, set against the complex and often messy realities (Biesta, 2010) of LD issues that we, along with our students, often experience.

Learning developers cannot however ignore the current political and social contexts that represent the environment within which our work exists. Nonetheless, LD practitioners must maintain their access to, engagement with, and production of a disparate range of research from across varied institutional and sectoral domains that go beyond seeking evidence of effectiveness. Hence, the need for and purpose of LD practitioner research is to create knowledge-of-practice (Cochrane-Smith and Lytle, 1999) that generates ontological understanding of, and exposure to, the epistemological bases of LD practices. 
Keywords: third space; practitioner-based research; cultural critics; identity.

\section{Introduction}

Through charting my own history of university employment, this commentary reflects on the relationship between professional identity and research in one of many learning development (LD) contexts. I will discuss how such roles encapsulated within LD operate within a third space that affords the opportunity to critique the cultures and practices LD practitioners experience for the benefit of our students, ourselves and our institutions. This process starts with considering what is meant by identity, how LD practitioners should use and conduct practitioner-based research, concluding that to counter the prevailing discourses that distort the value of LD researchers into technicists, we need to perceive ourselves as 'cultural critics' in the Academy (Ball, 2007).

\section{The context for my commentary}

Learning development (LD) as a field of practice can be seen as operating in the 'third space' of institutional or sector activity because it cuts across the traditional activities of research, teaching and either services, administration or knowledge transfer (Whitchurch, 2013). Indeed, those working in such roles are employed on a variety of academic, academic related, professional or non-academic contracts, within a range of institutional roles and departments that include lecturer, advisor, tutor, coach or trainer (Briggs, 2018). This represents a huge difference in how such provision operating in this way is conceptualised and delivered within universities (Pritchard, 2018), that are nonetheless increasingly conceived as highly collaborative roles enacting interdisciplinarity or even transdisciplinarity (Quinney et al., 2017). LD practitioners thus generate a wealth of experience and knowledge of different institutional and discipline-specific practices and cultures. Conceptualising LD as third space activity can allow one to view it as a site of negotiation, meaning-making and representation (Bhabba, 1990) that generates 'new ways of being, working and learning' (Solomon et al., 2006, p.6), and characterised as 'problem solving capability on the move' (Gibbons et al., 1994, p.5). 
Over the last ten years, I have fulfilled a learning developer role as a tutor on an academic contract at a small, local university in England. The university recruits high numbers of students identified as from households whose previous education occurred in state schools or colleges (99.6\%); whose main occupation is defined as routine, semi routine, technical or small employers (56.2\%); and whose neighbourhoods have low HE participation (18.6\%) (Higher Education Statistics Agency, 2018). Additionally, the university has a high proportion (76\%) of students commuting up to 57 miles to study (Donnelly and Gamsu, 2018). Within this arguably widening participation context, my professional responsibilities have shifted over time, however, they have all focused on undergraduate student retention at the institutional level. This initially involved developing, delivering and leading a suite of pre-entry courses and events for new level four, five and six undergraduates respectively, alongside leading a team of Academic Support Advisors who, together with students, review progress and advise on academic-related or personal issues that may be impacting on their studies. Now, however, my responsibilities have shifted to a more formal teaching role on Foundation Year programmes, as well as coordinating projects to support a growing understanding amongst staff of retention-related issues. These activities have all cut across areas of the wider institutional activity, necessitating close working with a range of professional, support and academic colleagues, as well as students themselves. This work requires me to utilise practical wisdom that involves intuitive thinking that is 'action-present' (Schön, 2001, p.198) which respects the communities students live in, and the inequalities they may often have faced upon accessing or participating in university. Thus, my work with students is informed by an awareness of their social and cultural situations and not exclusively based on knowledge contained within a 'closed' professional group that boasts 'technical or specialised body of knowledge' (Furlong, 2000, p 17). Hence, when attempting to align myself with traditional notions of professional identity, I have experienced difficulty echoing discussion that Briggs (2018) highlights within the Association for Learning Development in Higher Education community. My role, as do many, 'cuts across the dichotomies built into the positivist epistemology of practice' (Schön, 2001, p.189), raising questions about what I view 'professional identity' in this context to be. 


\section{Issues of Identity}

Identifying myself as a third space educational professional is problematic, not least because of the ways in which academic professional identities are normally understood and defined (Wenger, 1998; Whitchurch, 2013; Hustvelt, 2006). I find Quinn's (2010) discussion on four notions of self in terms of identity helpful here. The first concept of the 'authentic self' is founded on an autonomous sense of 'who we really are'. Secondly, the 'inescapable self' is bound by gender, ethnicity or class, unable to escape, and potentially disadvantaged in society by their demographical characteristic(s). Her third 'self-made self' concept is described as a project 'made over time' where, through reflexive narratives, one makes sense of experience that constantly sets new boundaries, that ultimately culminates in a sense of identity.

Quinn's fourth conception of the 'un-self' is described as 'a becoming' between multiplicities (Tamboukou, cited Quinn, 2010) that is constantly dissolving, diffusing and recreating itself in a perpetual process of flux. This resonates with Maclure's (2013) constantly shifting and expanding Cabinets of Curiosities that never congeal into 'fixities and definites' (Coleridge, cited Quinn, 2010, p.22). Indeed, I see these as analogous with that of professional academic identities: the wunderkammer, or wonder cabinet, (Maclure, 2013, p.180) was made up of diverse treasures with unanticipated associations that were simultaneously 'attuned to both classification and wonder [...through] eluding the collector's encyclopaedic ambitions' (Lugli in Maclure, 2013, p.180). Thus, if LD practitioners consider ourselves and the students we work with as Quinn's un-selves within this third space, we can acknowledge the power of education to both transform and simultaneously oppress, speaking to ideas of education as uncanny - that which is both familiar yet strange.

Here through Green (2011), in relation to the associated practices and cultures of dominant ideas of professional identity, I understand that what gives my own practice its sense and integrity lie beyond explicit speech or words. Indeed, I have been taken back to the Aristotelian concept of phronesis regarding the purpose of professional identities, understood here to mean 'practical wisdom based on the disposition to act truly and rightly' (Trotman, 2008, p.161). This concept rests on the notion that education - and facilitating student success within education - is in and of itself a public good. Using this concept, one could argue that LD roles potentially lead to human flourishing, that they are engaged in 
'professions of hope' (Freire, 2014), where education is both a service to and a right within society.

When viewing students or staff as 'un-selves' then, a translation of theories into practice is needed to enable LD practitioners to make judgements in what are sometimes, uncertain but immediate contexts (Baumfield, 2016). This creates a dialogical position; one that reveals the incoherence (Bohm et al., 1991) or contradictions in our thought and practices that are 'mutually constitutive' (Carr and Kemmis, 1986, pp.33-34). Here, the opportunity for on-the-spot inquiry occurs which Schön (2001) calls reflection-in-action: thinking that occurs when '... it is still possible to make a difference to the outcomes of action' (p.198). This I would argue is the intuition LD practitioners experience during the many interactions with students and staff occurring within practice, forming a 'bridge between tacit and explicit knowledge' (Moustakas, cited Trotman, 2008, p.159) and borne from an ability to operate reflexively. Such a way of working resists following prescribed sets of procedures or rules allowing us to notice 'what needs to be done and what end to pursue in the here and now' (Green, 2011, p.122).

\section{The value of learning development in neo-liberal times}

The context of LD work is surrounded by a pervasive moral panic (Cohen, 2011) espoused by politicians (see House of Lords Economics Affairs Committee Report, 2018) and fuelled by the media (for example: Adams, 2017; Sellgreen, 2018) that positions universities in England as 'not offering sufficient value for money' (MacFarlane, 2016, p.9). This is triggered by increasingly neo-liberal agendas for privatisation, globalisation and decentralisation of education (Naidoo and Whitty, 2014) that demand quantifiable outcomes across UK educational settings. Thus, there is an ever-growing sense that university study itself has been exposed to a process of what Lilley and Papadopoulos call 'biofinancialisation' (2014, pp.972-4). This presents the aim or value of participating in a university education - or indeed the recruitment of students into the university - as an essentially financial valuation, and depicted as more valuable than any other moral, ecological, cultural, material, utility and/or aesthetic value. This focus on value for money is reflected in the teaching excellence framework (TEF), meaning that universities are increasingly forced into taking student retention and performance very seriously due to the high cost of participation (Broadfoot, cited Thomas, 2012, p.1). 
Particularly for England, within such an era that is obsessed with 'value for money' (Gimyah, 2018), conducting LD work and research in the 'third space' is a challenge. This is because it is difficult to generate quantifiable evidence that correlates activities to improved performance in terms of retention, progression or degree level attainment of students. My view is that LD work in all its guises should regard its inherent value as generated from helping students to challenge or extend the received understandings of a particular topic (Collini, 2012), enabling them to contribute to society wherever they find themselves. Though perhaps mutually compatible, there are pressures for performance in terms of evidencing the effectiveness of LD activity that supports students staying, progressing and completing that potentially detracts from the actual needs and wants of students themselves.

To counter such pressure for evidence of LD effectiveness in the neo-liberal market place, it is crucial that the LD community accesses, influences and conducts situated practitioner research (Bamber, 2018) to enable understanding and analysis of our students' experiences as un-selves. Such research however must move beyond the neo-liberal ideals of 'causal or technological models of professional action' (Biesta, 2007, p.8) to assert LD practitioners as cultural critics. Here, LD practitioners can acknowledge the complexities of their world, reflexively casting doubt on knowledge production (Ball, 2007) experienced through work within the third space. Such work must focus on challenging the dominant practices and cultures to enable practical understanding and emancipatory reflective knowledge (Carr and Kemis, 1986) and explore how the diversity in experiences are generated, mediated and potentially overcome.

\section{Researching learning development within the third space}

Through systematic investigation into the variety of existing practices and beliefs with universities, LD research within the third space can therefore generate different ways of knowing through becoming what Ball calls a 'cultural critic' (2007, p.117). This resists the creation of 'knowledge-for-practice' (Cochrane-Smith and Lytle, 1999) that generates a discrete, explicit body of formal content knowledge or 'knowledge-in-practice' (CochraneSmith and Lytle, 1999) that exposes the indeterminate particularities of everyday life within LD contexts: these do not ask enough deeply critical questions about practice and cultures. This third space should produce research that Cochrane-Smith and Lytle (1999) 
describe as 'knowledge-of-practice'. This can move LD practices beyond technical-rational explanations of action or ideas of training, regarding both knowledge generation and knowledge use as inherently problematic because knowledge-creation does not exist as separate from the knower. Thus, the LD researcher is engaged in a different relationship with knowledge (Cochrane-smith and Lytle, 1999), creating what Scott et al. (2004) call 'Mode 4 knowledge'. Conceptualised as positioning the practitioner within practice, as well as across wider socio-economic and political contexts, this enables a critique of knowledge, necessitating self-examination and values-checking. Indeed, through engaging reflexively to understand our own LD behaviours; the practice of others and the experiences of those exposed to our practice, LD practitioners can come to understand 'profession' as a construct (Appleby and Pilkington, 2014, p.17).

Understanding LD practitioner-based knowledge-creation in this way can thus produce knowledge of how institutional systems and structures that inform practices and cultures go on to affect student experiences. This affords opportunities to investigate the supercomplexity or essential messiness of LD practice where thinking about LD can become more 'tentative, ambiguous and indeterminate' (Lauretis, 1990, p.138), and LD activities understood as a complex and self-perpetuating mix of both theory and practice (HickeyMoody and Malins, 2007). The purpose of this kind of LD research is therefore to foster understanding and improvement of practice, whilst at the same time develop knowledge of the epistemological bases of LD practice (Cochrane Smith and Lytle, 2009).

LD practitioners as social scientists then, should not solely focus on what works and why in relation to student success; an approach that promotes Cochrane-smith and Lytle's (1999) knowledge-in-practice and knowledge-for-practice model. Such approaches can perpetuate 'effectiveness research' (Ball, 2007, p.111) that apportions causality to what are complex interactions under investigation, including the external contexts of students and staff lives. Furthermore, focusing only on what works can privilege certain methodological approaches to research. For example, consider the Randomised Control Trial (RCT) that claims to test the effectiveness of educational interventions on student populations and seen as the gold standard (Gorard et al., 2017, pp.7-13) due to the perceived objectivity, generalisability and reliability within educational enquiry (Aldridge et al., 2018). However, even within the Health sciences where RCTs are commonplace, criticism concludes that there is an inherent trade-off between the ability to trace causal inference (internal validity) against generalisability (external validity). This means RCTs 
cannot actually identify exactly who benefits from an intervention: they can only offer central tendencies of a measure that is 'not going to be representative of anybody if you look at them as individuals' (Williams, cited Clay, 2010). Additionally, Brecker (cited Clay, 2010) asserts that 'the perfect RCT is designed strictly with internal validity in mind' and therefore, is not generalisable.

My argument here then is not to say LD researcher/practitioners can disconnect themselves from such drives for evidence of effectiveness or activities driven by what works rhetoric because they permeate the everyday professional experiences of university. However, what LD third space research approaches must critique are the dominant practices and cultures operating within university spaces that inhibit students' understanding, progression and success. This includes reflecting on LD practices and cultures themselves within universities, as well as those across the university that negate the complexity and indeterminacy of both student and staff lived experiences. Indeed, critiquing dominant practices and cultures within university spaces potentially assists in the reimagining of universities (Hilsdon, 2018) that can focus on 'the importance of education for decision, for rupture, for choice, for ethics' (Freire, 1997, p.44). Here, a student's understanding of themselves and the world around them, their growth and flourishing can happen. Furthermore, LD practitioners too can reflexively act 'upon the world in order to transform it' (Freire, 1972, p.12) through their critique that Foucault argues is 'urgent, difficult yet quite possible' (1988, p.154).

\section{References}

Adams, R. (2017) 'University students failed by rip-off fees, says watchdog', The Guardian Education, 8 December. Available at: https://www.theguardian.com/education/2017/dec/08/university-students-failed-byrip-off-fees-says-watchdog (Accessed: 20 August 2018).

Aldridge, R., Biesta, G. and Wainwright, E. (2018) 'Why the nature of educational research should remain contested: a statement from the new editors of the British Educational Research Journal', British Educational Research Association Journal, 44(1), pp. 1-4. 
Appleby, Y. and Pilkington, R. (2014) Developing critical professional practice in education. Leicester: NIACE.

Ball, S. (2007) 'Intellectuals or technicians? The urgent role of theory in educational studies', in Hammersley, M. (ed.) Educational research and evidence-based practice. London: Open University Press/Sage, pp 106-120

Bamber, R. (2018) 'Tectonic shifts in HE = tectonic shifts in learning development?' [keynote address], ALDinHE 2018: The Learning Development Conference, University of Leicester, Leicester 26-28 March.

Baumfield, V. (2016) Lost in translation? Sharing knowledge and experiences of curriculum development in teacher education and medical education in the UK, 25 November. Birmingham: Newman University.

Bhabba, H. (1990) 'The Third Space: interview with Homi Bhabba' in Rutherford, J. (ed.) Identity: community, culture, difference. London: Lawrence and Wishart, pp. 207-21.

Biesta, G. (2007) 'Why 'What Works' won't work: evidence-based practice and the democratic deficit in educational research', Educational Theory, 1(57), pp. 1-22.

Biesta, G. (2010) 'Five theses on complexity reduction and its politics' in Osberg, D. and Biesta, G. (eds.) Complexity theory and the politics of education. Rotterdam: Sense Publishers, pp. 5-14.

Bohm, D., Factor, D. and Garrett, P. (1991) 'dialogue - a proposal', Infed.org: Pedagogies for Change. Available at: http://infed.org/archives/e-texts/bohm dialogue.htm (Accessed 04.01.17)

Briggs, S. (2018) 'Development of the ALDinHE recognition scheme: certifying the 'learner developer' title', Journal of Learning Development in Higher Education, Issue 13, April. Available at: http://journal.aldinhe.ac.uk/index.php/ildhe/article/view/461/pdf (Accessed: 3 August 2018).

Carr, W. and Kemmis, S. (1986) Becoming critical. London: Falmer Press. 
Clay, R (2010) 'More than one way to measure', Monitor on Psychology, 41(8), p. 52.

Available at: http://www.apa.org/monitor/2010/09/trials.aspx (Accessed: 26 June 2018).

Cochran-Smith, M. and Lytle, P. (1999) 'Relationships of knowledge and practice: teacher learning in communities', Review of Research in Education: Toward a New Science of Educational Practice, 24(1), pp. 249-305.

Cochran-Smith, M. and Lytle, P. (2009) Inquiry as stance: practitioner for the next generation. New York: Teachers College Press.

Cohen, S. (2011) Folk devils and moral panics. London: Routledge.

Collini, S. (2012) What are universities for? London: Penguin.

Donnelly, M. and Gamsu, S. (2018) Home and away: social, ethnic and spatial inequalities in student mobility, University of Bath and The Sutton Trust. Available at: https://www.suttontrust.com/wpcontent/uploads/2018/02/Home and away FINAL.pdf (Accessed: 16 May 2018).

Foucault, M. (1988) 'Truth, power, self: an interview with Michel Foucault', Technologies of the Self. Amherst: The University of Massachusetts Press.

Freire, P. (1972) Pedagogy of the oppressed, Harmondsworth: Penguin, London.

Freire, P. (1997) Pedagogy of the Heart, New York: Continuum

Freire, P. (2014) Pedagogy of hope. London: Bloomsbury.

Furlong, J. (2000) 'Intuition and the crisis in teacher professionalism' in Atkinson, T. and Claxton, G. (eds.) The intuitive practitioner: on the value of not always knowing what one is doing. New York: Open University Press, pp 15-32 
Gibbons, M., Limoges, C., Nowotony, H., Schwartzman, S., Scott, P. and Trow, M. (1994) The new production of knowledge: the dynamics of science and research in contemporary societies. London: Sage Publications.

Gimyah, S. (2018) 'Delivering value for money in the age of the student', HEPI Annual Conference. London 7 June. Available at: https://www.gov.uk/government/speeches/delivering-value-for-money-in-the-age-ofthe-student (Accessed: 15 June 2018).

Gorard, S., Huat See, B. and Siddiqui, N. (2017) The trials of evidence-based education: the promises, opportunities and problems of trials in education. Oxon: Routledge.

Green, J. (2011) Education, professionalism and the quest for accountability: hitting the target but missing the point. London: Routledge.

Hickey-Moody, A. and Malins, P. (eds.) (2007) Deleuzian encounters: studies in contemporary social issues. Basingstoke: Palgrave Macmillan.

Higher Education Statistics Agency - HESA (2018) Widening participation (Table Series 1 and 2). Available at: https://www.hesa.ac.uk/data-and-analysis/performanceindicators/widening-participation (Accessed: 5 January 2018).

Hilsdon, J. (2018) 'Learning development: pedagogy, principles and progress' [keynote address], ALDinHE 2018: The Learning Development Conference. University of Leicester, Leicester 26-28 March.

House of Lords Economics Affairs Committee (2018) Treating students fairly: the economics of post-school education. Available at: https://www.parliament.uk/higherfurther-education-vocational-lords-inquiry/ (Accessed: 11 June 2018).

Hustvelt, S. (2006) A plea for Eros. London: Hodder and Stoughton Limited.

Lauretis, D. (1990) 'Eccentric subjects: feminist theory and historical consciousness', Feminist Studies, 16(1), pp. 133-146. 
Lilley, S. and Papadopoulos, D. (2014) 'Material returns: cultures of valuation, biofinancialisation and the autonomy of politics', Sociology, 48(5), pp. 972-988. Available at: https://doi.org/10.1177/0038038514539206 (Accessed: 10 June 2018).

MacFarlane, B. (2016) Freedom to learn: the threat to student academic freedom and why it needs to be reclaimed. Research into Higher Education. Oxon: Routledge.

Maclure, M. (2013) 'Classification or wonder? Coding as an analytic practice in qualitative research', in Coleman, R. and Ringrose, J. (eds.) Deleuze and research methodologies. Edinburgh: Edinburgh University Press, pp 164-183

Naidoo, R. and Whitty, G. (2014) 'Students as consumers: commodifying or democratising learning?', International Journal of Chinese Education, 2(2), pp. 212-240. Available at: https://doi.org/10.1163/22125868-12340022 (Accessed: 24 July 2018).

Pritchard, C. (2018) 'Locating learning development in higher education: can you ever have enough learning developers?', ALDinHE 2018: The Learning Development Conference. University of Leicester, Leicester, 26-28 March.

Quinn, J. (2010) Learning communities and imagined social capital. London: Continuum Studies in Educational Research.

Quinney, A., Lamont, C., Biggins, D. and Holley, D. (2017) 'Optimising disruptive approaches: extending academic roles and identities in higher education', Journal of Learning Development in Higher Education, Issue 12, November, pp. 1-14. Available at: http://journal.aldinhe.ac.uk/index.php/jldhe/article/view/417 (Accessed: 3 August 2018).

Schön, D. (2001) 'Chapter 13: The crisis of professional knowledge and the pursuit of an epistemology of practice', in Raven, J. and Stephenson, J. (eds.), Competence in the learning society. New York: Peter Lang, pp. 185-207.

Scott, D., Brown, A., Lunt, I. and Thorne, L. (2004) Professional doctorates: integrating professional and academic knowledge. Maidenhead: Society for Research in Higher Education/Open University Press. 
Sellgreen, K. (2018) 'Tuition fee value for money: I feel ripped off', BBC News Family and Education, 14 March (Online). Available at: https://www.bbc.co.uk/news/education43384427 (Accessed: 20 August 2018).

Solomon, N., Boud, D. and Rooney, D. (2006) 'The in-between: exposing everyday learning at work', International Journal of Lifelong Education, 25(1), pp. 3-13.

Thomas, L. (2012) Building student engagement and belonging in higher education at a time of change: a summary of findings and recommendations from the What Works? Student Retention \& Success programme. Paul Hamlyn Foundation. Available at: http://www.phf.org.uk/wp-content/uploads/2014/10/What-WorksSummary-report.pdf (Accessed: 20 January 2016).

Trotman, D. (2008) Liberating the wise educator', in Craft, A., Gardner, H. and Claxton, G. (eds.) Creativity, wisdom and trusteeship: exploring the role of education. London: Sage, pp. 158-166

Wenger, E. (1998) Communities of practice: learning, meaning and identity. Cambridge: Cambridge University Press.

Whitchurch, C. (2013) Reconstructing identities in higher education: the rise of third space professionals. London: SRHE.

\section{Author details}

Sarah Parkes teaches on Foundation Year routes at Newman University, having previously led the university's participation in the HEA \& Paul Hamlyn 'What Works: Student Retention and Success Change Programme' (2012-16) and HEFCE Catalyst Project 'Using Student Engagement data to inform pedagogic innovation' (2016-18). Her principal interests lie in curriculum design and institutional organisation that pro-actively supports student navigation of university experience. 